\title{
Survey of Utah High School Football Strength and Conditioning Coaches
}

\author{
Eugene Keoki Weaver ${ }^{1}$ and Mark DeBeliso ${ }^{2}$ \\ 1. Sports Performance Training, Dixie Regional Medical Center, Intermountain Healthcare, St. George UT 84790, USA \\ 2. Department of Physical Education and Human Performance, Southern Utah University, Cedar City UT 84720, USA
}

\begin{abstract}
Strength and conditioning coaches have become a vital part of sport programs. The majority of college and professional teams have one or more strength and conditioning coaches on their staff. Currently there is limited information on the profile of high school strength and conditioning coaches. This study provides a profile, which can be used by state athletic associations, school districts, athletic directors, and head coaches, to determine the desired criteria for high school strength and conditioning coaches. This study also provides future coaches with a guide to help them become appealing candidates for positions as high school strength and conditioning coaches. PURPOSE: The purpose of this study was to identify the individual responsible for designing and implementing the football strength and conditioning programs in Utah high schools and provide a profile of the coach and the program. METHODS: The participants were high school football strength and conditioning coaches in the state of Utah. Participants were asked to complete an online survey. RESULTS: Thirty-six percent (36/100) of the surveys were completed and useable for the study. Eighty seven percent of the respondents identified the strength and conditioning coach as their secondary position in the football program. All $(n=36)$ of the respondents held at least a Bachelor degree and a majority $(61.1 \%)$ held a graduate degree. Physical Education was the most widely reported major in undergraduate degrees, while the majority of graduate degrees were in areas outside of the physical education/exercise field (63.6\%). A total of $64.5 \%$ of the respondents did not hold a strength and conditioning certification. Strength and conditioning experience ranged from 30 to 2 years among respondents. CONCLUSION: Within the parameters of this study, a profile of the coaches and the respective strength and conditioning programs has been provided. The data culled during this study is inconclusive with respect to the preparation of coaches and administration of strength and conditioning protocols with respect to team wins and losses.
\end{abstract}

Key words: High school football, Utah, strength and conditioning.

\section{Introduction}

According to the NFHS (National Federation of High Schools), during the 2013-2014 school year, 14,048 high schools in the United States participated in football [1]. In Utah, during the 2013-2014 school year, 103 high schools participated in football according the UHSAA (Utah High School Athletic Association) [2].

The responsibility of the strength and conditioning coach is to provide training programs to maximize the athlete's ability (strength, power, speed) and transfer

Corresponding author: Mark DeBeliso, Ph.D., research fields: orthopedic biomechanics, mechanics and metabolics of sport movements and work-tasks, strength training for all walks of life, and master's athletes. E-mail: markdebeliso@suu.edu. that to the playing field, bringing optimal sport performance [3-5]. Strength and conditioning coaches have become an integral part of professional and collegiate programs. The majority of college and professional teams have one or more strength and conditioning coaches on their staff and the majority of these individuals have a sport performance certification and a degree in exercise science or related field [3-5]. Many high school coaches and administrators believe that anyone with an athletic background or muscular build can adequately run a strength and conditioning program [6]. This is not saying that these individuals are inadequate as strength and conditioning coaches, but research has shown that certified and educated strength and 
conditioning coaches provide a higher percentage of safe and effective programs [9]. With continued research done in the area of sport performance there has been a need for coaches with certification and a more extensive educational background. A minimum of a bachelor's degree in physical education or exercise science is occasionally preferred for high school positions and a master's degree is preferred for the collegiate and professional $[5,7,8]$.

In 1985, the NSCA (National Strength and Conditioning Associations) created the CSCS (Certified Strength and Conditioning Specialist) certification. This certification was designed to identify individuals that possess the competence to design and implement safe and effective strength and conditioning programs. While some consider the CSCS the gold standard in strength and conditioning, other organizations have certifications that are creditable and require extensive knowledge in sports performance. USA Weightlifting offers a sport performance certification and the CSCCa (Collegiate Strength and Conditioning Coaches Association) also have their own certification that is specific to college coaches. The practices of high school strength coaches are greatly influenced by their college and professional counterparts [8]. With this guidance from college and professional coaches, the assumption would be that high school strength coaches would also have the same certifications and educational backgrounds.

Strength and Conditioning coaches may use a variety of techniques and training methods in their program. Plyometric training, Olympic lifting, and Periodization are a few of the training techniques a coach may use. Many high school coaches gather their information on advanced techniques and methods from college and professional coaches and/or the Strength and Conditioning Journal, published by the NSCA [8].

Plyometric training techniques have shown to increase agility and power, which can be transferred to the playing field [10]. The NSCA position statement on plyometrics states that a plyometric training program is important for most competitive sports, especially those involving running, jumping and rapid changes in direction and can improve athletic performance. Research supports the combination of resistance training and plyometric training as an effective means of improving sport performance [10].

Olympic lifting is also popular among strength and conditioning coaches and has the potential to increase force production [11]. Olympic lifts educate athletes on how to apply and receive force [19]. Olympic lifts also provide athletes with the ability to accelerate under different degrees of resistance. Some individuals responsible for the strength and conditioning program may feel uncomfortable implementing Olympic lifts. This may be because the individual does not understand the purpose of Olympic lifts or is not able to teach proper techniques of Olympic lifts.

Periodization has been universally acknowledged as a training strategy for athletes regardless of skill level [12]. It is very challenging for coaches to develop programs that offer continuous progression while avoiding overtraining, within the high school setting. Young athletes may participate in multiple sports throughout the school year, which would limit pre-season or post-season training.

Sports nutrition is an important part of athletics. Many athletes look to their coaches for advice on nutrition and supplementation [13]. Coaches may or may not have the adequate training and education to prescribe a dietary guideline for athletes.

During the 2013-2014 school year, Utah was divided into 6 classifications (5A, 4A, 3AA, 3A, 2A, 1A). Utah's 103 schools are spread over hundreds of miles. Utah has a mix of large and small schools in both urban and rural settings. The school size and geography determines what classification they are placed in [2].

Currently there is a lack of information available on strength and conditioning programs in Utah high 
schools. To our knowledge, there are three studies that are focused primarily on high school strength and conditioning coaches $[7,14,15]$.

Duehring et al. [7] provided a profile of high school strength and conditioning coaches in the United States. Although the study provides a profile of high school strength and conditioning practices, it is limited to only members of the National Strength and Conditioning Association. Reynolds et al. [14] surveyed high school strength and conditioning coaches in Idaho. The study provided a profile of both men's and women's strength and conditioning coaches. The study was focused on gender differences of male and female coaches and limited to a three county area in Idaho. Finamore [15] surveyed high school football strength and conditioning coaches in Massachusetts. The survey was limited to practices and injury rates of athletes.

Given the paucity information regarding high school coaches' strength and conditioning profiles, the purpose of this study was to identify the individual responsible for designing and implementing the strength and conditioning programs in Utah high schools (football) and provide a profile of coaches.

The results of this study can be used by state athletic associations, school districts, athletic directors, and head coaches, to determine the desired criteria for high school strength and conditioning coaches. This study also provides future coaches with a guide to help them become appealing candidates for positions as high school strength and conditioning coaches.

\section{Methods}

The participants are high school football strength and conditioning coaches in the state of Utah. Contact was made via email to the high school football coach to determine to individual responsible for the strength and conditioning program. Once the appropriate individual was identified, contact was made via email to the strength and conditioning coach to participate in study. A hyperlink to the questionnaire was included in the email. Within the email, an explanation outlining the purpose of the study was provided. It was assumed that the participants consented to participate when they completed the questionnaire for this study. Participation was on a volunteer basis, and no compensation was provided for participating in the study. The study was approved by the University Institutional Review Board for the protection of human subjects. The participants included full time employees, part time employees, and volunteers of the high school football program. SurveyMonkey was used as the online survey tool.

The questionnaire surveyed the demographics, education, certification, experience, techniques used, outcomes and opinions. The validity of the questionnaire is enhanced by comprehensive literature review. To insure reliability the questionnaire was pilot-tested on a small sample of Utah high school strength and conditioning coaches.

Data analysis was conducted on the completed surveys. The data analysis first looked at the basic results for each question. Mean and standard deviation were used on all pertinent questions and other information was reported in frequencies.

\section{Results}

Of the 100 surveys sent out, 36 were completed and useable for the study. All coaches that participated in the survey $(n=36)$ are of the male gender. The majority of coaches surveyed are in 30-39 (34.3\%) and 40-49 (48.6\%) age categories. Table 1 presents the age categories of coaches surveyed.

Table 1 Age Category.

\begin{tabular}{lll}
\hline Answer Choices & Responses & $\#$ \\
\hline 17 or younger & $0.00 \%$ & 0 \\
$18-20$ & $0.00 \%$ & 0 \\
$21-29$ & $2.86 \%$ & 1 \\
$30-39$ & $34.29 \%$ & 12 \\
$40-49$ & $48.57 \%$ & 17 \\
$50-59$ & $14.29 \%$ & 5 \\
60 or older & $0.00 \%$ & 0 \\
Total & & 35 \\
\hline
\end{tabular}


A majority $(87.5 \%)$ of coaches of the coaches identified the strength and conditioning coach as their secondary position and $2.8 \%$ of the respondents identified the Strength and Conditioning coach as their primary position. The majority $(94.4 \%)$ of coaches surveyed are employed full-time at their high school. Part-time and volunteer positions were very low, with one coach in each category.

Each area of the community (urban, urban/rural, rural, and private) was represented in the survey, with $33.3 \%$ from urban areas, $27.8 \%$ urban/rural areas, and $33.3 \%$ from rural areas. Two private schools were also represented.

All of the coaches $(n=36)$ held at least a Bachelor degree and a majority (61.1\%) held a graduate degree. Physical Education was the most commonly reported major in undergraduate degrees, while the majority of graduate degrees are in areas outside of the physical education/exercise field (63.6\%). Tables 2 and 3 present the education majors of both undergraduate and graduate degrees.

Very few coaches held certifications, with $64.5 \%$ having no certification in providing strength training. The NSCA's CSCS certification was the most reported with $16.1 \% .9$ of the coaches with strength certifications are at least 40 years old and only 1 coach was under 40 with a certification. Table 4 presents the strength training credentials of participating coaches.

Strength and conditioning experience ranges from 30 to 2 years among participating coaches. The mean for years of experience was 13.8 years and a standard deviation of 8.0 , while the mode was 15 years of experience. Twenty-two (61.1\%) of coaches coached more than one sport at their high school. Other experience included that $50.0 \%$ of participants had worked as a strength and conditioning coach at another high school, while $5.6 \%$ previously worked at the college level and one coach had previous experience at the professional level. The survey also showed that 5 of the coaches had experience in strength training at a sports performance training facility.

A majority (97.1\%) of coaches performed fitness tests on their athletes. Of the coaches that performed tests $(n=34)$, strength $(100 \%)$, power $(85.3 \%)$, speed $(94.1 \%)$, and agility $(88.2 \%)$ were the most reported tests. Endurance (55.9\%) and flexibility $(47.1 \%)$ were reported to a lesser amount. Coaches reported using clinics (28.6\%), books, (25.7\%) and college coaches

Table 2 Undergraduate Degree.

\begin{tabular}{lll}
\hline Answer Choices & Responses & $\#$ \\
\hline Strength and Conditioning & $0.00 \%$ & 0 \\
Exercise Science & $5.56 \%$ & 2 \\
Physical Education & $52.78 \%$ & 19 \\
Athletic Training & $2.78 \%$ & 1 \\
Health and Wellness & $2.78 \%$ & 1 \\
Physical Therapy & $0.00 \%$ & 0 \\
None of the above & $36.11 \%$ & 13 \\
Total & & 36 \\
\hline
\end{tabular}

Table 3 Graduate Degree.

\begin{tabular}{lll}
\hline Answer Choices & Responses & $\#$ \\
\hline Strength and Conditioning & $9.09 \%$ & 3 \\
Exercise Science & $3.03 \%$ & 1 \\
Physical Education & $24.24 \%$ & 8 \\
Athletic Training & $0.00 \%$ & 0 \\
Health and Wellness & $0.00 \%$ & 0 \\
Physical Therapy & $0.00 \%$ & 0 \\
None of the above & $63.64 \%$ & 21 \\
Total & & 33 \\
\hline
\end{tabular}

Table 4 Certifications.

\begin{tabular}{lll}
\hline Answer Choices & Responses & $\#$ \\
\hline ACSM-Personal Trainer & $0.00 \%$ & 0 \\
ACSM-Health Fitness & $12.90 \%$ & 4 \\
Instructor & $3.23 \%$ & 1 \\
ACSM-Exercise Specialist & $0.00 \%$ & 0 \\
ACSM-Other & $3.23 \%$ & 1 \\
CSCCa-S\&C & $0.00 \%$ & 0 \\
CSCCa-Master S\&C & $0.00 \%$ & 0 \\
NASM-PES & $0.00 \%$ & 0 \\
NASM-Other & $0.00 \%$ & 0 \\
NSCA-Personal Trainer & $16.13 \%$ & 5 \\
NSCA-CSCS & $6.45 \%$ & 2 \\
USA Weightlifting - CC & $0.00 \%$ & 0 \\
USA Weightlifting-NC & $6.45 \%$ & 2 \\
USA Weightlifting-SPC & $64.52 \%$ & 20 \\
No Certification & & 31 \\
Total & &
\end{tabular}


$(17.1 \%)$ as the most used source when developing and conducting fitness tests. Ten out of 11 (90.1\%) coaches certified in strength training used all of the advanced training techniques within their program and 11 out of $25(40.0 \%)$ coaches without a strength certification use a majority of advanced training techniques. Table 5 presents the different sources that coaches use to develop and conduct fitness tests.

Coaches that used all of the advanced techniques ( $n$ $=24$ ) averaged 15.0 years of experience with a standard deviation of 7.3 and coaches that did not use a majority of advanced techniques $(n=10)$ averaged 11.7 years of experience with a standard deviation of 9.5. An independent t-test comparing experience and the use of advanced techniques, showed no significant difference between the groups $(P=0.32)$. Coaches that used all of the advanced techniques were equally divided among the different type of school district areas. Urban areas included $8(33.3 \%)$ of the coaches and urban/rural and rural areas included 7 (29.1\%) coaches.

A majority $(97.1 \%)$ of the coaches use plyometric training in their program and a majority $(62.9 \%)$ has had formal training in plyometrics. The most popular sources of information for developing plyometric programs are clinics (22.9\%), professional journals (20.0\%), books (17.1\%), and college coaches (14.3\%).

Table 6 presents the sources of information coaches use to develop plyometric programs.

Olympic lifts are used by most of the coaches (91.4\%) and majority (72.7\%) have had formal training. Clinics (35.5\%) and college coaches (29.0\%) are the most popular source of information in developing Olympic lifts training. Table 7 presents the sources of information coaches use to develop Olympic lifts training.

Most $(82.9 \%)$ of the coaches use periodization in their program and a little more than half $(51.4 \%)$ has had formal training in periodization. Clinics, books, and college coaches continue to be a popular source of information in developing periodization programs.
Table 8 presents the sources of information coaches have used in developing periodization programs.

Almost all (97.1\%) of the coaches use speed and agility training in their program and a majority $(68.6 \%)$ has had formal training in speed and agility training.

Table 5 Sources Information: Developing Fitness Tests.

\begin{tabular}{lll}
\hline Answer Choices & Responses & $\#$ \\
\hline High School Coaches & $11.43 \%$ & 4 \\
College Coaches & $17.14 \%$ & 6 \\
Professional Coaches & $5.71 \%$ & 2 \\
Professional Journals & $8.57 \%$ & 3 \\
Books & $25.71 \%$ & 9 \\
Clinics & $28.57 \%$ & 10 \\
Magazines & $2.86 \%$ & 1 \\
Total & & 35 \\
\hline
\end{tabular}

Table 6 Sources Information: Plyometric Training.

\begin{tabular}{lll}
\hline Answer Choices & Responses & $\#$ \\
\hline High School Coaches & $11.43 \%$ & 4 \\
College Coaches & $14.29 \%$ & 5 \\
Professional Coaches & $8.57 \%$ & 3 \\
Professional Journals & $20.00 \%$ & 7 \\
Books & $17.14 \%$ & 6 \\
Clinics & $22.86 \%$ & 8 \\
Magazines & $5.71 \%$ & 2 \\
Total & & 35 \\
\hline
\end{tabular}

Table 7 Sources Information: Olympic Lifting.

\begin{tabular}{lll}
\hline Answer Choices & Responses & $\#$ \\
\hline High School Coaches & $3.23 \%$ & 1 \\
College Coaches & $29.03 \%$ & 9 \\
Professional Coaches & $9.68 \%$ & 3 \\
Professional Journals & $6.45 \%$ & 2 \\
Books & $12.90 \%$ & 4 \\
Clinics & $35.48 \%$ & 11 \\
Magazines & $3.23 \%$ & 1 \\
Total & & 31 \\
\hline
\end{tabular}

Table 8 Sources Information: Periodization.

\begin{tabular}{lll}
\hline Answer Choices & Responses & $\#$ \\
\hline High School Coaches & $6.90 \%$ & 2 \\
College Coaches & $27.59 \%$ & 8 \\
Professional Coaches & $3.45 \%$ & 1 \\
Professional Journals & $6.90 \%$ & 2 \\
Books & $27.59 \%$ & 8 \\
Clinics & $27.59 \%$ & 8 \\
Magazines & $0.00 \%$ & 0 \\
Total & & 29 \\
\hline
\end{tabular}


Clinics (32.4\%) and college coaches (20.6\%) are the most popular source in providing information in speed and agility training. Table 9 presents the sources in providing information in speed and agility training.

A majority $(85.7 \%)$ of coaches provide nutritional advice to their athletes and more than half $(54.3 \%)$ have had formal training in sports nutrition. Clinics are the most popular source used by coaches, with $30.3 \%$ using this mode as a source of information. Professional Journals are the second most popular source with $21.2 \%$ of coaches using this avenue in providing information in sports nutrition. Table 10 presents the sources that provide information in sports nutrition to coaches.

A majority (65.7\%) of high school coaches reported that the school has one weight room, and $28.6 \%$ reported having two weight rooms. One coach also reported to have three weight rooms.

Coaches reported that all facilities contained free weights, 91.4\% contained Olympic equipment, $80 \%$ contained resistance machines, $60 \%$ contained resistance bands, $48.6 \%$ contained stability balls, $76.3 \%$ contained medicine balls, $91.4 \%$ contained agility ladders, and $71.4 \%$ contained hurdles. These results showed that most weight rooms have an adequate amount of equipment. This correlates with responses from coaches, in which $74.3 \%$ reported to have an adequate amount of equipment and $25.7 \%$ reported to have a deficient amount of equipment.

Success on the football field, ranged from 0 to 13 wins during the 2013 high school football season. The mean number of wins among respondents is 6.6 with a standard deviation of 3.5. There are two modes of 4 and 5 wins among the coaches participating in the survey. 80.0\% of teams made the 2013 playoffs, according the coaches participating in the survey. $25.7 \%$ reached the 2013 semi-finals and 5 teams won the 2013 state championship in their classification. This shows that 5 out of 6 classification (5A, 4A, 3AA, $3 \mathrm{~A}, 2 \mathrm{~A}$, and $1 \mathrm{~A})$ champions participated in this survey.
Almost half (16) of the teams have made the playoffs every year for the last 5 years. Eight teams have made the playoffs 4 out of 5 years. Four teams made the playoffs 3 out of 5 years. Two teams made the playoffs 2 out of 5 years. Two teams made the playoffs 1 out of 5 years and 3 teams have not made the playoffs in the last 5 years.

Coaches with a certification $(n=11)$ averaged 7.8 wins last season with a standard deviation of 3.5 and coaches without certification $(n=24)$ averaged 6.5 wins with a standard deviation of 3.5. An independent t-test $(P=0.33)$ comparing certification/wins and no certification/wins showed there was no significant difference between the groups.

Coaches with a degree in Physical Education or exercise related field $(n=23)$ averaged 6.5 wins last season with a standard deviation of 3.4 and coaches with a degree outside of exercise $(n=12)$ averaged 6.9 wins with a standard deviation of 3.5. An independent t-test $(P=0.73)$ comparing wins of the two groups, showed no significant difference between groups. Coaches with at least a graduate degree $(n=21)$

Table 9 Sources Information: Speed \& Agility Training.

\begin{tabular}{lll}
\hline Answer Choices & Responses & $\#$ \\
\hline High School Coaches & $14.71 \%$ & 5 \\
College Coaches & $20.59 \%$ & 7 \\
Professional Coaches & $14.71 \%$ & 5 \\
Professional Journals & $2.94 \%$ & 1 \\
Books & $14.71 \%$ & 5 \\
Clinics & $32.35 \%$ & 11 \\
Magazines & $0.00 \%$ & 0 \\
Total & & 34 \\
\hline
\end{tabular}

Table 10 Sources Information: Sports Nutrition.

\begin{tabular}{lll}
\hline Answer Choices & Responses & $\#$ \\
\hline High School Coaches & $12.12 \%$ & 4 \\
College Coaches & $15.15 \%$ & 5 \\
Professional Coaches & $6.06 \%$ & 2 \\
Professional Journals & $21.21 \%$ & 7 \\
Books & $30.30 \%$ & 10 \\
Clinics & $15.15 \%$ & 5 \\
Magazines & $0.00 \%$ & 0 \\
Total & & 33 \\
\hline
\end{tabular}


Table 11 Strongest Areas of their Strength and Conditioning Program.

\begin{tabular}{lll}
\hline Answer Choices & Responses & $\#$ \\
\hline Equipment Available & $35.29 \%$ & 12 \\
Space Available & $29.41 \%$ & 10 \\
Quality of Coaching & $67.65 \%$ & 23 \\
Training Techniques & $70.59 \%$ & 24 \\
Athletes believe in program & $76.47 \%$ & 26 \\
Support from school admin. & $38.24 \%$ & 13 \\
No strong areas & $2.94 \%$ & 1 \\
Total responses 33 & & \\
\hline
\end{tabular}

averaged 6.4 wins with a standard deviation of 3.5 and coaches with a bachelor's degree or less $(n=14)$ averaged 7 wins with a standard deviation of 3.3. Again, an independent t-test comparing the two groups showed no significant difference $(P=0.61)$.

Coaches that used advanced training techniques $(n$ $=24)$ in their program averaged 7 wins with a standard deviation of 3.2. Coaches that did not incorporate a majority of advanced training techniques $(n=10)$ in their programs averaged 5.3 wins with a standard deviation of 3.6. An independent t-test $(P=$ 0.19 ) found no significant difference between the two groups.

All of participating coaches believe that their strength and conditioning program has improved performance, while $97.1 \%$ also believe that their strength and conditioning program has reduced or prevented injuries. Responding coaches believe the three strongest areas of their program are: "Athletes believe in the program" (76.5\%), "Training techniques" (70.6\%), and "Quality of coaching" $(67.7 \%)$. Table 11 presents the data on the coach's opinions on the strongest areas of their programs.

Half $(50 \%)$ of the coaches believe the weakest area of their program is "Space available" and $44.1 \%$ of coaches stated that lack equipment is the weakest area. Coaches also ranked the biggest restrictions to their program (1 being the most important): 1-Money, 2-Equipment, 3-Coaches, 4-Administration, and 5-Time.

According to coaches the most important goals/benefits of their strength and conditioning program in the following order ( 1 being the most important): 1-Enhanced/Improved athletic performance, 2-Injury prevention/reduction, 3-Increased strength/power/mass. Coaches also ranked the most vital criteria for a strength and conditioning coach. Education was ranked as the most vital criteria, followed by experience and certification.

\section{Discussion}

This study was conducted to investigate the practices of Utah high school football strength and conditioning coaches. Demographics, education, certification, experience, practices, outcomes, and opinions of strength and conditioning coaches were identified through an online survey. Previous research $[7,14,15]$ has been conducted on high school strength and conditioning practices, yet no research has been conducted on Utah high school football strength and conditioning practices. Therefore, it is important for athletic directors, coaches, strength and conditioning educators, and future strength and conditioning coaches, to be cognizant of the profile and practices of current coaches.

It was interesting that only one participant reported that the position of strength and conditioning coach was their primary position in the football program. The majority of the coaches that participated in the survey reported that their primary position was head coach of the football team, compared favorably to a previous study [15] in which $69 \%$ of the coaches were also the head football coach.

An objective of this study was to answer the question of "What certifications, if any, do the high school football strength and conditioning coaches in Utah have?" The study showed that only $35.4 \%$ ( $n=$ 11) coaches have a certification and $16.1 \%(n=5)$ have that certification as a CSCS. This is considerably lower when compared to previous study [7], in which $97 \%$ of all participants held a certification. Although the aforementioned study demonstrated a significantly higher percentage of certified practitioners [7], it is 
most likely due to the survey population (NSCA-members) that was used for their study.

The results of the education level of coaches are very comparable to a previous study [7]. The previous study showed that all of the coaches held at least a bachelor's degree and 55.3\% held a master's degree [7], compared to this survey, in which all coaches held a bachelor's degree and $61.1 \%$ held a masters degree. In the current study $63.9 \%$ of the participating coaches held a bachelor's degree in physical education or exercise related degree. This was lower than a previous study, which reported that the majority $(84 \%)$ of surveyed coaches held a bachelor's degree in Physical Education or exercise related degree [7]. Education and certification may have some association as 8 out of 11 coaches that held a strength certification also held a graduate degree. Also, all $(n=$ 5) of the coaches that held a CSCS certification also held a graduate degree.

Coach's experience in strength and conditioning averaged 13.8 years in the current study and was similar to that reported (14.9 years) in a previous study [7]. It was interesting that coaches that made the semi-finals $(n=9)$ averaged 15.8 years of experience, compared to 10.3 years for coaches that did not make the playoffs $(n=7)$.

\subsection{Practices}

Research suggests that strength training along with the use of plyometrics, Olympic lifts, periodization, speed and agility training, and sports nutrition have a profound benefit on athletic performance [10, 16-18]. Therefore, it is encouraging that the majority of strength and conditioning coaches implement these training practices along in their strength program. All ( $n=5$ ) coaches that are CSCS certified use the advanced training techniques in their program, which may be due to additional education provided by those taking the CSCS exam. Also, the majority of coaches that held a graduate degree used advanced training techniques in their programs. Since there are always new strength training strategies and programs being developed, it would be beneficial for coaches to stay current on these strategies and programs through education and certifications.

One potential area of concern maybe sports nutrition. $30(85.7 \%)$ of coaches that responded to the survey provide their athletes with nutrition recommendations, but only 19 of those coaches have had formal training in sports nutrition. With these results, what information are coaches giving to their athletes in regard to sports nutrition? And with the majority of coaches providing nutrition information, should there be some type of requirement that coaches receive formal training in sports nutrition?

Another area that may be of concern is periodization. $29(82.9 \%)$ of coaches use periodization techniques, while only 18 of those coaches have had formal training. This reinforces the importance of coaches to continue to stay current on the latest research and practices in strength and conditioning, through education and certifications.

Having a strength certification seems to influence what type of information source the coaches use to develop their programs. Coaches with strength certifications $(n=11)$ are more likely to use many sources of information (journals, books, clinics, coaches, etc.) in developing their programs. Journals are the overwhelming source of information for coaches with CSCS certification $(n=5)$ and coaches without strength certifications $(n=20)$ tend to use clinics as the most popular source of information in developing most of their programs.

\subsection{Facilities}

All but one of the coaches participating in the survey has at least one or more weight training facilities. Many of the coaches believe that their program could be improved with more coaches, equipment, and space. The opinions of the coaches, in respect to their training facilities, were as expected related to their success rate on the football field. All ( $n$ 
$=7$ ) of the coaches with teams that did not make the playoffs believed that their athletes did not have adequate strength and conditioning equipment, while all the coaches $(n=9)$ that made the semi-finals believed they had adequate strength and conditioning equipment to train their athletes.

\subsection{Opinions}

Coach's opinions on the most important criteria for strength and conditioning coaches are consistent with their responses to education, experience, and certification. Coaches ranked education and experience as the most important and certification ranked third in a majority of coaches that participated in the survey. What is also interesting is that all coaches that held a certification ranked certification as 3rd most important criteria. Nineteen of the coaches ranked education as the most important criteria, while fourteen coaches ranked experience as the most important. Only one coach ranked certification as the most important criteria and three ranked it as the second most important. Unless certification is recognized and/or required by high schools, it will continue to be low on a priority list for coaches.

Nearly all of the coaches reported that the strength and conditioning coach was a secondary position for them in the football program. Most $(n=35)$ of the participants are also the head coach, which was consistent with the opinion that there is a need for more strength coaches.

\section{Conclusions}

The profile average, for Utah high school football strength and conditioning coaches that responded to the survey, is between 40-49 years old and has dual roles as head football and strength coach. They also hold bachelors degree in Physical Education and do not hold a strength and conditioning certification. The profile also averaged 7 wins in football last year and has 14 years of experience in strength and conditioning training.
Currently, there are no state web sites that track information on strength and conditioning coaches at the high school level. Also, in Utah there are no guidelines or requirements that are in place to insure that strength and conditioning programs are safe for athletes.

Unfortunately, this survey could not determine if the quality of strength and conditioning programs related to an effective and safe program. But it was disappointing, to the author, that very few of the coaches surveyed held a certification in strength and conditioning. Although the author would have preferred a larger response rate, the survey nevertheless provided a comprehensive profile of Utah high school football strength and conditioning coaches and also the only one to date.

In the future, it could be advantageous to expand the survey to other high school sports in Utah. It would also be beneficial to include in the survey questions that examined the injury rates and types of injuries. The survey could also explore actual fitness levels of athletes as a possible metric of success with regards to determining if coaches holding a certification in strength and conditioning is meritorious.

With the limited information on the profile of high school strength and conditioning coaches, this survey serves as a source of information describing the background, practices, and opinions of Utah high school football strength and conditioning coaches. This survey can provide a template for additional strength and conditioning surveys conducted on high school sports. This study provides information that can be also useful in developing standards in education, experience, and certification of high school strength and conditioning coaches. This survey can be used to compare Utah high school strength and conditioning coaches to Division I, II, or III football strength coaches. Likewise, the results of this survey may provide in depth analysis of any deficiencies in Utah high school programs as individual high schools 
can directly compare and contrast their strength and conditioning program with the results of this survey. Comparisons can also be made with other sports, states, and level of competition. This study also provides future coaches with a guide to help them become appealing candidates for positions as high school strength and conditioning coaches. This survey may also be useful to anyone contemplating about starting a career as a strength and conditioning coach at Utah high schools.

\section{References}

[1] National Federation of State High School Associations. 2013. "NFHS: Participation Data, 2012-2013 High School Athletics Participation Survey Results." Accessed September 29, 2013. http://www.nfhs.org/content.aspx?id=3282

[2] Utah High School Activities Association. 2013. "2013-14 UHSAA Handbook." Accessed October 20, 2013. http://uhsaa.org/Publications/Handbook/Handbook.pdf

[3] Massey, C. D., Vincent, J., and Maneval, M. 2004. "Job Analysis of College Division I-A Football Strength and Conditioning Coaches." Journal of Strength and Conditioning Research 18 (1): 19-25.

[4] Massey, C. D., Schwind, J. J., Andrews, D. C., and Maneval, M. W. 2009. "An Analysis of the Job of Strength and Conditioning Coach for Football at the Division II Level." Journal of Strength and Conditioning Research 23 (9): 2493-9.

[5] Sutherland, T. M., and Wiley, J. P. 1997. "Survey of Strength and Conditioning Services for Professional Athletes in Four Sports." Journal of Strength and Conditioning Research 11 (4): 266-8.

[6] Reverter-Masia, J., Legaz-Arrese, A., Munguia-Izquierdo, D., Barbany, J. R., and Serrano-Ostariz, E. 2009. “A Profile of the Resistance Training Practices of Elite Spanish Club Teams." Journal of Strength and Conditioning Research 25 (3): 1537-47.

[7] Duehring, M. D., Feldmann, C. R., and Ebben, W. P. 2009. "Strength and Conditioning Practices of United States High School Strength and Conditioning Coaches." Journal of Strength and Conditioning Research 23 (8): 2188-203.

[8] Durell, D. L., Pujol, T. J., and Barnes, J. T. 2003. “A Survey of the Scientific Data and Training Methods Utilized by Collegiate Strength and Conditioning Coaches." Journal of Strength and Conditioning
Research 17 (2): 368-73.

[9] McGladrey, B. W. 2010. "High School Physical Educators' and Sport Coaches' Knowledge of Strength Training Principles and Methods." Unpublished doctoral dissertation, University of Utah.

[10] Potach, D. H., and Chu, D. A. 2008. "Plyometric training" In: Essentials of Strength Training and Conditioning 3rd ed. Champaign, IL: Human Kinetics, 413-56.

[11] Haff, G. G., Whitley, A., and Potteiger, J. A. 2001. "A Brief Review: Explosive Exercises and Sports Performance." Strength and Conditioning Journal 23 (3): 13-20.

[12] Wathen, D., Baechle, T. R., and Earle, R. W. 2008. Periodization: Essentials of Strength Training and Conditioning 3rd ed. Champaign, IL: Human Kinetics, 507-22.

[13] Baer, J. T., Dean, D. J., and Lambrinides, T. 1994. "How High School Football Coaches Recommend Their Players Gain Lean Body Mass." Journal of Strength and Conditioning Research 8 (2): 72-5.

[14] Reynolds, M. L., Ransdell, L. B., Lucas, S. M., Petlichkoff, L. M., and Gao, Y. 2012. "An Examination of Current Practices and Gender Differences in Strength and Conditioning in a Sample of Varsity High School Athletic Programs." Journal of Strength and Conditioning Research 26 (1): 174-83.

[15] Finamore, L. V. 1992. "Survey of High School Football Team Strength and Conditioning Programs." Journal of Athletic Training 27 (2): 125-30.

[16] Hori, N., Newton, R., Andrews, W. A., Kawamori, N., McGuigan, M. R., and Nosaka, K. 2008. "Does Performance of Hang Power Clean Differentiate Performance of Jumping, Sprinting, and Changing of Direction?" Journal of Strength and Conditioning Research 22 (2): 412-8.

[17] Rhea, M. R., Phillips, W. T., Burkett, L. N., Stone, W. J., Ball, S. D., Alvar, B. A., and Thomas, A. B. 2003. "A Comparison of Linear and Daily Undulating Periodized Programs with Equated Volume and Intensity for Local Muscular Endurance." Journal of Strength and Conditioning Research 17 (1): 82-7.

[18] Duellman, M. C., Lukaszuk, J. M., Prawitz, A. D., and Brandenburg, J. P. 2008. "Protein Supplement Users among High School Athletes Have Misconceptions about Effectiveness." Journal of Strength and Conditioning Research 22 (4): 1124-9.

[19] Hoffman, J. R., Cooper, J., Wendell, M., and Kang, J. 2004. "Comparison of Olympic vs. Traditional Lifting Training Programs in Football Players." Journal of Strength and Conditioning Research 18 (1): 129-35. 